\title{
Stimulus selection and the number of stimulus components*
}

\author{
JACK RICHARDSON \\ State University of New York at Binghamton, Binghamton, New York 13901
}

\begin{abstract}
The number of word components in the compound stimuli of paired-associate lists were varied, and the words within a compound were presented either in a constant or in a variable order from trial to trial. The number of components, above one, had no appreciable effect on the difficulty of learning, and the variable order lists were more difficult than the constant order. Recall with the word components as cues showed that the amount of selection decreased with the variable order lists as the number of components increased. With the constant order lists, selection tended to remain constant as number of components increased. This was interpreted as the result of the availability of a rule for selection in the constant order conditions.
\end{abstract}

Martin (1968) has maintained that the number of possible encodings of the stimuli may be inversely related to performance on a paired-associate list, and Butler and Merikle (1970) have provided some direct evidence that is consistent with this view. Although studies of stimulus selection are sometimes used as a basis for making inferences about encoding (e.g., Williams \& Underwood, 1970), most of the studies have used stimulus compounds consisting of two or three components, and there has been no systematic investigation of the effect of the number of components.

Within the framework presented earlier (Richardson, 1972), it seemed that the number of components in a stimulus compound might not affect selection if there was a simple rule of selection available, such as "select the letters in the third position of the trigrams." In fact, it seemed possible that increasing the number of components might encourage Ss to apply a rule of selection earlier in learning and thus increase the amount of selection. On the other hand, if the presentation of the stimuli does not permit the use of a rule of selection, increasing the number of stimulus components should decrease the amount of selection. The selection of a component is more difficult, and during learning the $\mathrm{S}$ must examine more components to find the selected one.

It has been shown (Richardson, 1972) that trigram stimuli in which the relative position of the three letters in the trigrams change from trial to trial make a paired-associate list more difficult to learn and produce less selection than trigram stimuli that remain the same on each trial. In the present study, it was assumed that varying the position of the components in a stimulus compound so that Ss could not predict the position of any particular component would eliminate the use of any systematic rule of selection. The first experiment in the present study varied the number of words in the compound stimuli and presented the words in a

*This research was supported by Grant GB-17614 from the National Science Foundation. Daniel $L$. Yeager collected the data and assisted in the statistical analy sis. compound in either the same or different sequences from trial to trial. The second experiment added a lower degree of learning in an attempt to determine if the less efficient selection in the variable position condition occurred early in learning or developed as learning progressed.

\section{EXPERIMENT I}

\section{Method}

Design and Lists. The conditions were defined by seven types of paired-associate lists learned by separate groups of Ss. All lists consisted of eight pairs with words as stimuli and the digits 1 through 8 as responses. The stimulus items of a list consisted of 2,3 , or 6 words, and these were combined with a constant (C) or variable (V) order of words within a stimulus item from trial to trial of learning. In addition to these six conditions, a seventh condition required learning a list with single words as stimulus items.

Fortyeight common four-letter nouns with no obvious associations were used to construct the stimulus items. The 48 nouns were randomly divided into eight compounds of six words with the restriction that an initial letter of a word could not be repeated as an initial letter of another word within a compound. The digits 1 through 8 were randomly assigned to the compounds as responses. For the lists with stimulus items consisting of less than six words, the appropriate number of words was selected by starting with the words in the last position of the six-word compounds and working back toward the beginning. For example, the three-word stimuli consisted of the last three words from each of the six-word stimuli. This procedure was repeated with the same 48 nouns so that there were two lists used equally often within each of the seven conditions.

Procedure. All paired-associate lists were presented on a Stowe memory drum by the study-test method at a 2 -sec rate with a 2 -sec intercycle interval to a criterion of two successive perfect trials. There were six different random orders of the pairs used for the study cycles and another six for the test cycles. In the $C$ conditions, the words of a compound were in the same order, from left to right, on all study and test cycles. In the $V$ conditions, the order of the words within a compound varied from cycle to cycle. In the lists with six-word stimuli, 12 of the possible permutations of a compound were chosen, and in the lists with three words as stimuli, all 6 permutations were used. The initial word of a compound was not the same on both the study and test cycles of a trial. In the $V$ conditions with two words as stimulus items, the sequence of the two words was 
Table 1

Experiment I: Mean Trials to Criterion, Total Correct Recall, Different Correct Recall, and Efficiency Scores

Fxperiment I: Number of Components

\begin{tabular}{|c|c|c|c|c|c|c|c|c|c|}
\hline \multirow{3}{*}{$\begin{array}{l}\text { Response } \\
\text { Measure }\end{array}$} & \multirow[b]{3}{*}{ Position } & \multirow{2}{*}{\multicolumn{2}{|c|}{1}} & \multirow{2}{*}{\multicolumn{2}{|c|}{2}} & \multirow{2}{*}{\multicolumn{2}{|c|}{3}} & \multirow{2}{*}{\multicolumn{2}{|c|}{6}} \\
\hline & & & & & & & & & \\
\hline & & $\mathbf{M}$ & $\sigma$ & M & $\sigma$ & $\mathbf{M}$ & $\sigma$ & $\mathbf{M}$ & $\sigma$ \\
\hline $\begin{array}{l}\text { Trials to } \\
\text { Criterion }\end{array}$ & $\begin{array}{l}\text { Constant } \\
\text { Variable }\end{array}$ & 6.83 & $\begin{array}{l}3.06 \\
-\end{array}$ & $\begin{array}{l}12.00 \\
16.62\end{array}$ & $\begin{array}{r}7.47 \\
10.11\end{array}$ & $\begin{array}{l}12.92 \\
18.79\end{array}$ & $\begin{array}{r}11.63 \\
8.72\end{array}$ & $\begin{array}{l}13.21 \\
18.92\end{array}$ & $\begin{array}{r}8.18 \\
12.22\end{array}$ \\
\hline $\begin{array}{l}\text { Total } \\
\text { Recall, } 2 / 3\end{array}$ & $\begin{array}{l}\text { Constant } \\
\text { Variable }\end{array}$ & $\begin{array}{c}10.58 \\
-\end{array}$ & $\begin{array}{c}1.84 \\
-\end{array}$ & $\begin{array}{l}11.25 \\
11.12\end{array}$ & $\begin{array}{l}2.83 \\
3.07\end{array}$ & $\begin{array}{l}10.67 \\
13.67\end{array}$ & $\begin{array}{l}3.00 \\
3.57\end{array}$ & $\begin{array}{l}11.67 \\
15.71\end{array}$ & $\begin{array}{l}2.63 \\
3.03\end{array}$ \\
\hline $\begin{array}{l}\text { Different } \\
\text { Recall, } 2 / 3\end{array}$ & $\begin{array}{l}\text { Constant } \\
\text { Variable }\end{array}$ & $\begin{array}{l}7.71 \\
-\end{array}$ & $\begin{array}{l}.69 \\
-\end{array}$ & $\begin{array}{l}6.67 \\
6.71\end{array}$ & $\begin{array}{l}1.09 \\
1.12\end{array}$ & $\begin{array}{l}7.08 \\
7.33\end{array}$ & $\begin{array}{r}1.10 \\
.92\end{array}$ & $\begin{array}{l}7.46 \\
7.62\end{array}$ & $\begin{array}{l}.78 \\
.65\end{array}$ \\
\hline $\begin{array}{l}\text { Efficiency, } \\
2 / 3\end{array}$ & $\begin{array}{l}\text { Constant } \\
\text { Variable }\end{array}$ & ${ }^{75}$ & $\begin{array}{c}10.80 \\
-\end{array}$ & $\begin{array}{l}61 \\
63\end{array}$ & $\begin{array}{r}9.76 \\
12.56\end{array}$ & $\begin{array}{l}70 \\
57\end{array}$ & $\begin{array}{l}13.23 \\
14.49\end{array}$ & $\begin{array}{l}67 \\
50\end{array}$ & $\begin{array}{l}14.43 \\
10.33\end{array}$ \\
\hline
\end{tabular}

randomly assigned for each of the 96 stimulus presentations.

In the $\mathrm{V}$ conditions, the number of stimulus components and number of different sequences of the components within a compound were confounded. However, the important point is that $S$ should not be able to predict the position of a component in a compound in any of the $\mathrm{V}$ conditions. The use of six different random orders of the pairs for study cycles and for test cycles prevented prediction of which stimulus would appear next. The order of the components not only varied from cycle to cycle but were varied independently within cycles so that knowledge of the order of the components in one compound gave no information concerning the order of the components in the next compound. It was assumed that this variation in presentation of the stimulus components effectively prevented prediction of the position of the components in all $V$ conditions and thus prohibited the use of a systematic rule of selection.

The usual paired-associate instructions were used, and Ss were not told that they would be required to recall following learning of the list. After the learning of the paired-associate list, the $\mathbf{4 8}$ stimulus words were presented individually for three recall trials. The position of the words within the compound for the $\mathrm{C}$ lists was counterbalanced within trials, and a different order of the 48 words was used for each trial. An equal number of Ss within each condition received each possible sequence of the three recall orders. The words were typed on cards, and Ss were required to turn the cards up one at a time and attempt to give the digit that had been paired with the word during learning. If they did not know the correct digit or thought the word had not appeared in the paired-associate list, they were required to guess one of the digits 1 through 8 . The Ss were given no information concerning the correctness of the responses during the three recall trials, and all responses were recorded by $E$.

Subjects. The Ss were college students and were assigned as they appeared at the laboratory to conditions that had been listed in counterbalanced orders. In addition to the $168 \mathrm{Ss}$ who completed the experiment, 12 for each of two lists in seven conditions, 9 were dropped, 4 because of malfunction of the memory drum, 3 because of E's scheduling errors, 1 asked to leave before the end of the experiment, and 1 failed to learn in 100 trials. In each case, these Ss were replaced by the next $S$ to appear at the laboratory.

\section{Results}

In general, the lists with single words as stimuli (Condition 1C) had a smaller variance than the other lists, so they were compared with the lists with two-word stimuli in constant position (Condition $2 \mathrm{C}$ ) in a separate analysis for each response measure. The major analysis excluded Condition $1 \mathrm{C}$ and was a 3 by 2 by 2 factorial, 2, 3, or 6 words as compound stimuli, constant or varied position of the components, and two lists.
Learning. The results of Experiment I are presented in Table 1 and the mean trials required to attain the criterion of two successive perfect trials are in the first two rows of the body of the table. The $1 \mathrm{C}$ condition produced faster learning than the $2 \mathrm{C}, \mathrm{F}(1,44)=10.29$, $\mathrm{p}<.01$, and this agrees with previous comparisons of paired-associate lists with single components and compounds as stimuli (Richardson, 1972). There was an increase in the number of trials to criterion as the number of components increased from 2 to 6 , but this trend did not approach significance, $F(2,132)<1.00$. As expected, the $\mathrm{V}$ condition was more difficult than the $\mathrm{C}$ condition, $F(1,132)=10.97, p<.01$. The only other significant source of variance was the $C \cdot V$ by List interaction, $F(1,132)=6.11, p<.05$. At first this significant interaction of $\mathrm{C}-\mathrm{V}$ and list seems strange, but Ss who learned the $\mathrm{C}$ lists tended to select words in either the first or last position as the functional stimuli, while Ss who learned the $V$ lists could not use a position rule and selected from among the components available. Thus, even though the nominal stimulus words were the same, $S s$ in the $C$ and $V$ conditions simply learned lists with different words as functional stimuli. The result of the different selection in the $\mathrm{C}$ and $\mathrm{V}$ conditions was that one list was more difficult in the $C$ condition and the other list was more difficult in the $\mathrm{V}$ condition. The same significant $C-V$ by List interaction occurred in Experiment II.

Recall. A digit recall to a stimulus word was scored as correct only if it was correct on at least two of the three recall trials. The mean total number of recall responses correct to the $2 / 3$ criterion are presented in Table 1 . The difference between Conditions $1 \mathrm{C}$ and $2 \mathrm{C}$ did not approach significance. The mean recall increased as the number of components increased, $F(2,132)=8.38$, $p<.01$, and there was more recall in the $V$ condition than in the $C, F(1,132)=21.05, p<.01$. However, examination of the means in Table 1 shows that recall increased as the number of components increased in the $V$ condition, but not in the $C$. This was supported by the significant $\mathrm{C}-\mathrm{V}$ by Number of Components interaction, $F(2,132)=6.21, p<.01$.

The mean number of different correct recall responses are presented in Table 1 and are the mean number of 
pairs for which one or more of the word components elicited a correct digit response on at least two of the three recall trials. The mean different correct recall responses tend to increase as the number of components increase from 2 to 6 . The small estimates of the population standard deviation shown in the table were produced by the fact that 87 of the 168 Ss recalled all eight different items. This ceiling effect reduced the variance, so the usual statistical tests were not useful. A chi square computed on the number of Ss who had all eight of the different recall responses correct showed that more Ss made perfect scores in Condition 1C than in $2 \mathrm{C}, \chi^{2}(1)=14.08, p<.01$, and that the number of Ss with perfect scores increased as the number of components increased from 2 to $6, \chi^{2}(2)=16.94$, $\mathrm{p}<.01$.

Efficiency. The efficiency score is the percentage of the total correct recall responses to the word components that would be necessary for $S$ to give a single correct response to each learning stimulus that is represented by a correct recall to one or more of the word components. An efficiency score was computed for each $\mathrm{S}$ by dividing the number of different correct recall responses by the total number of correct recall responses and multiplying the result by 100 . The recall to a word was scored as correct only if it was given correctly on at least two of the three recall trials. The efficiency scores are presented in the last two rows of Table 1. Condition 1C was more efficient than $2 \mathrm{C}$, $\mathrm{F}(1,44)=19.20, \mathrm{p}<.01$, and the $\mathrm{C}$ conditions were more efficient than the $V$ conditions, $F(1,132)=19.47$, $p<.01$. The main effect of number of components, as the number of components increased from 2 to 6 , did not approach significance. However, there was a tendency for the $\mathrm{C}$ conditions to increase in efficiency and for the $\mathrm{V}$ conditions to decrease in efficiency. This was reflected in the interaction between number of components and $\mathrm{C}-\mathrm{V}, \mathrm{F}(2,132)=6.93, \mathrm{p}<.01$.

A test of the effect of number of components within the $\mathrm{C}$ and $\mathrm{V}$ conditions showed that the decrease in the $\mathrm{V}$ condition was significant, $\mathrm{F}(2,132)=6.05, \mathrm{p}<.01$, and that the increase in the $\mathrm{C}$ condition did not attain significance at the .05 level, $F(2,132)=2.73, \mathrm{p}<.10$.

Examination of Table 1 shows that decreased efficiency was associated with an increased number of different responses recalled. It might be reasonable to assume that the differences in efficiency tend to reflect the ceiling effect in the number of different responses recalled. As a check on this, the same analyses were computed on efficiency scores based on a $3 / 3$ criterion, i.e., a recall to a word component was scored as correct only if the response was given correctly on all three trials. The higher criterion of correct recall lowered the number of different correct responses so that the variability was not as restricted. The os of the number of different responses ranged from 1.27 to 1.76 in the six conditions. The mean efficiency scores based on the $3 / 3$ criterion were 71,83 , and 82 for the 2,3 , and 6 components of the $\mathrm{C}$ conditions and 75,72 , and 66 for the comparable $\mathrm{V}$ conditions. The analysis showed that $\mathrm{C}-\mathrm{V}, \mathrm{F}(1,132)=10.20, \mathrm{p}<.01$, and the Number of Components by $\mathrm{C}-\mathrm{V}$ interaction, $\mathrm{F}(2,132)=6.44$, $\mathrm{p}<.01$, were significant sources of variance, the same sources as with efficiency scores based on the $2 / 3$ criterion of recall. However, tests of the effect of number of components within the $\mathrm{C}$ and $\mathrm{V}$ conditions gave reversed results. The increase in efficiency as number of components increased was significant within the $C$ condition, $F(2,132)=5.16, p<.01$, but the decrease within the $\mathrm{V}$ condition was not, $\mathrm{F}(2,132)=$ $2.77, \mathrm{p}<.10$.

The next experiment replicated the $\mathrm{C}$ and $\mathrm{V}$ conditions with six stimulus components to check on the stability of the results of Experiment $I$ and also added a lower degree of learning to determine if the difference between the efficiency of selection in the $\mathrm{C}$ and $\mathrm{V}$ conditions increased during the paired-associate learning.

\section{EXPERIMENT II}

\section{Method}

The $6 \mathrm{C}$ and $6 \mathrm{~V}$ lists were learned to a criterion of two successive perfect trials, as in Experiment $I$, or to a criterion of four correct responses on a single trial. All details of the procedure were the same as in Experiment I, and 24 Ss were assigned to each of the four basic conditions. In addition to the 96 Ss who completed the experiment, 2 were replaced, 1 because of a malfunction of the memory drum and the second because the experimental session was interrupted by the evacuation of the building due to a bomb threat.

\section{Results}

The results are presented in Table 2. The means for the groups that learned to a criterion of two successive perfect trials did not differ appreciably from the comparable six-word stimulus conditions of Experiment I.

In addition to the obviously larger number of trials required to learn to the higher degree of learning, the $\mathrm{V}$ condition required more trials to learn than the $\mathrm{C}$, $F(1,88)=12.15, p<.01$, and the $C-V$ by List interaction was significant as discussed in Experiment $\mathrm{I}$, $\mathrm{F}(1,88)=4.45, \mathrm{p}<.05$. This merely replicates the learning results of Experiment $\mathrm{I}$.

The total recall responses correct to the $2 / 3$ criterion show more correct recalls for the higher degree of learning, $F(1,88)=93.79, p<.01$, and more correct recalls for the $\mathrm{V}$ than the $\mathrm{C}$ condition, $\mathrm{F}(1,88)=16.70$, $\mathrm{p}<.01$. The Degree of Learning by $\mathrm{C} \cdot \mathrm{V}$ interaction was also significant, $F(1,88)=4.93, p<.05$, showing that, as degree of learning increased, the total correct recall increased more for the $\mathrm{V}$ condition than for the $\mathrm{C}$ condition.

The mean number of different correct recalls are also shown in Table 2, but, as in Experiment I, the variance in the conditions with learning to two successive perfect trials was reduced by a ceiling effect. The efficiency 
Table 2

Experiment II: Mean Trials to Criterion, Total Correct Recall, Different Correct Recall, and Efficiency Scores

\begin{tabular}{llrrrrr} 
& & \multicolumn{4}{c}{$\begin{array}{c}\text { Experiment II } \\
\text { Degree of Learning }\end{array}$} \\
\cline { 3 - 6 } Response & & \multicolumn{2}{c}{2 Perfect } & & \multicolumn{2}{c}{$4 / 8$} \\
\cline { 3 - 4 } \cline { 5 - 6 } Measure & Position & \multicolumn{1}{c}{$\mathrm{M}$} & $\sigma$ & & \multicolumn{1}{c}{$\mathrm{M}$} & $\sigma$ \\
\hline Trials to & Constant & 14.17 & 6.12 & 5.50 & 5.37 \\
Criterion & Variable & 19.67 & 8.45 & 10.12 & 8.49 \\
Total & Constant & 11.17 & 2.16 & 6.33 & 3.33 \\
Recall, 2/3 & Variable & 15.25 & 3.79 & 7.54 & 3.13 \\
Different & Constant & 7.21 & .98 & 4.33 & 1.58 \\
Recall, 2/3 & Variable & 7.50 & .72 & 5.21 & 1.50 \\
Efficiency, & Constant & 66 & 11.43 & 73 & 17.21 \\
$2 / 3$ & Variable & 52 & 10.71 & 74 & 16.72 \\
\hline
\end{tabular}

scores based on the $2 / 3$ recall are presented in the last two rows of Table 2 . The mean efficiency score was larger at the lower criterion of learning, $F(1,88)=23.07$, $p<.01$, and for the $C$ condition, $F(1,88)=5.21$, $\mathrm{p}<.05$. The higher efficiency for the $\mathrm{C}$ condition was produced entirely by the difference at the higher degree of learning, $F(1,88)=7.16, p<.01$, for the interaction of $\mathrm{C}-\mathrm{V}$ and degree of learning. The efficiency was the same for the $C$ and $V$ conditions at the $4 / 8$ criterion of learning, and the $\mathrm{V}$ condition decreased more than the $\mathrm{C}$ as learning increased to two successive perfect trials.

\section{Discussion}

The results clearly support the conclusion (Richardson, 1972) that paired-associate lists with compound stimuli tend to be more difficult to learn and produce less selection than those with single components as stimuli. However, when the number of components in a compound was varied from 2 to 6 , there was no significant increase in the difficulty of learning and the selection effects depended upon whether or not a rule of selection was available to $S$.

The results suggest that a two-component compound may be atypical in that a rule of selection provides very little advantage in terms of efficiency of selection. With more than two components in a compound, a rule of selection makes learning and efficiency independent of the number of components. However, without a rule of selection, learning is more difficult and efficiency decreases as the number of components increases.

Table 2 shows that the difference in difficulty of the constant and variable conditions was as large at the $4 / 8$ criterion as at the two successive perfect. The efficiency of the constant and variable conditions was the same at the lower criterion of learning and differed at the higher criterion. The advantage of the availability of a rule of selection for learning occurred early and the difference in efficiency occurred later in learning. This suggests that the difference in difficulty of the constant and varied lists may be primarily due to the difficulty of selecting a single word as the functional stimulus. The difference in efficiency occurs later and may be the result of different processes in the two conditions. In the constant condition Ss may, in some cases, learn the response to a component prior to the use of a rule of selection. After a few trials, Ss apply the rule of selection, and this enables them to learn to the selected components without searching through the nonselected components. Thus, further learning to nonselected components is minimized (Richardson, 1973). On the other hand, the variable position conditions prohibit the use of a consistent rule of selection, and $S$ must continue to search for the selected components each time the compound is presented. Incidental learning may occur during the search for the selected component. The more components in a compound stimulus, the more the learning during the search, and the net result is lower efficiency.

Wolfgang and Richardson (in press) have shown that rules for selecting components are not restricted to simple perceptual rules. They found that Ss selected color names as functional stimuli from word compounds in preference to selecting on the basis of position. Thus the selection was on the basis of a $\mathrm{S}$ category and not on a physical aspect of the compound. This may make stimulus selection more plausible as an analogue of encoding, but the results of the present experiment should not be considered evidence against Martin's (1968) encoding variability hypothesis. He mentioned number of possible functional encodings, but it was clear that he was dealing with probability distributions of encodings that are presumably subject to change by the context. The present study of stimulus selection, as well as other studies, tend to support Martin's general position in that much of the differences in difficulty of paired-associate lists is due to the selection stage rather than the associative stage. Perhaps the selection stage corresponds to Martin's E Phase.

\section{REFERENCES}

Butler, B. E., \& Merikle, P. M. Uncertainty and meaningfulness in paired-associate learning. Joumal of Verbal Learning \& Verbal Behavior, 1970, 9, 634-641.

Martin, E. Stimulus meaningfulness and paired-associate transfer: An encoding variability hypothesis. Psychological Review, $1968,75,421-441$.

Richardson, J. Stimulus selection in associative learning. In C. P. Duncan, L. Sechrest, and A. W. Melton (Eds.), Human memory: Festschrift for Benton J. Underwood. New York: Appleton-Century-Crofts, 1972

Richardson, J. Effect of speed of learning and degree of learning on cue selection. Journal of Experimental Psychology, 1973, $98,396-403$.

Williams, R. F., \& Underwood, B. J. Encoding variability: Tests of the Martin hypothesis. Journal of Experimental Psychology, 1970, 86, 317-324.

Wolfgang, A. K., \& Richardson, J. Effect of type of stimulus component on cue selection. American Journal of Psychology, in press.

(Received for publication July 5, 1973; revision received November 26, 1973.) 